\title{
Resilience planning, a facilitated modelling approach
}

\author{
Hugo Herrera 1,2, ${ }^{*}$, Birgit Kopanisky² \\ 1 University of Palermo, Department DEMS Via Ugo Antonio Amico 3, 90100 Palermo, Italy \\ 2 University of Bergen, Department of Geogrphay, System Dynamics Group, Fosswinckelsgate 6, N-5007 \\ Bergen, Norway \\ * Correspondence: hugo.leon@student.uib.no
}

Keywords: Resilience, participation, planning, food systems

\begin{abstract}
Resilience has emerged as a buzzword among researchers and practitioners. However, despite its popularity, there has been little progress in moving it from an elaborate metaphor describing an idyllic state of the system to a tool for planning and managing adaptation. While case study research is rich with examples of systems that have proven to be resilient or are striving to develop resilience, there is no defined approach that operationalises concepts described in the literature into the planning process. This paper helps close this gap by illustrating how facilitated modelling can be used for resilience planning in socio-ecological systems. The paper summarizes our experience using facilitated system dynamics to inform a model-based discussion of food security resilience to climate change in Guatemala. We identify at least three positive outcomes from the intervention, which a) helped to build consensus about the meaning of resilience, b) improved stakeholders understanding of adaptation and c) outlined potential policies to enhance resilience.
\end{abstract}

\section{INTRODUCTION}

To address climate change effects in socio-ecological systems (SESs), it is necessary to go beyond conventional policymaking approaches, and there is an urgent need to change the way adaptation is approached (Perrings, 1998; Schmidhuber \& Tubiello, 2007). In response to this need, resilience has gained popularity as a new framework for planning adaptation (Davoudi, Brooks, \& Mehmood, 2013; Tompkins \& Adger, 2004). Resilience describes a system's capacity to absorb disturbance and to reorganise in order to adapt to new conditions (Folke, 2006; Walker et al., 2002; Walker, Holling, Carpenter, \& Kinzig, 2004).

In simple terms, resilience provides insights into at least three different states of the system. First, resilience provides a useful analytical framework for identifying ways of stabilising the system's outcomes despite the presence of disturbances. Often referred to as system stability 
or robustness (Herrera, 2017a; Walker et al., 2004), this capacity to withstand disturbances is fundamental for mitigating risk and securing essential system outcomes such as food and water. Second, the resilience framework can be used to explore the "ability of a system to return to an equilibrium state after a temporary disturbance" (Holling, 1973, p. 17). This ability to persist is a cornerstone for adaptation, and there is a justified interest in understanding the mechanisms that help a system recover and to do it as fast, as feasibly, and as sustainably as possible.

Finally, resilience provides insights into how systems transform when they are pushed beyond their limits (Folke, Carpenter, Walker, Scheffer, \& Chapin, 2010). Transformability has been defined by Walker et al. (2004, p. 5) as "the capacity to create a fundamentally new system when ecological, economic, or social structures make the existing system untenable". If climate conditions change beyond the system's capacity to adapt, new processes, structures and institutions will be needed for human subsistence.

While the abovementioned versatility of the resilience concept for a holistic approach to adaptation make it appealing to researchers and practitioners, its application continues to be underdeveloped (Davoudi et al., 2012; Pizzo, 2015). The lack of application is at least partially due to the complications associated with operationalising the concept of resilience and the lack of approaches for supporting policymakers in understanding resilience and the complex systems they deal with (Marshall \& Marshall, 2007).

By compiling experience documented in case study research, the first steps towards such an approach have been taken. For instance, case study research suggests that planning for resilience should be informed or fully developed with stakeholder input (Walker et al., 2002). The current limited understanding about the social aspects of SESs and the high social and political stakes in these systems means that the discussion of resilience is likely to be contested and that participation is needed to democratise outcomes and reduce conflict (Biggs et al., 2012).

There are also some suggestions in the literature that these processes might involve using mathematical models for supporting resilience analysis (see, for example, Hawes \& Reed, 2006; Walker et al., 2002). This assumption is justified by the difficulties in identifying thresholds and adequately anticipating the system's behaviours (Folke et al., 2010; Marshall and Marshall, 2007). Moreover, there is a long history of modelling to help manage natural resources in similar circumstances. 
However, despite these first steps towards integrating facilitated modelling and resilience frameworks, there is still a ways to go (Davoudi et al., 2012; Duit, 2015). For example, the practicalities about when and how stakeholders should be involved have not been openly discussed (Duit, 2015). Similarly, while the application of models in natural resource management is extensive, their application in resilience is limited to only a few examples, and the methodological questions about how to conceptualise resilience in mathematical models remain (Davoudi et al., 2012; Marshall \& Marshall, 2007).

With the aim to close these gaps in the literature, this paper takes a step forward in integrating participatory modelling into the resilience framework. Namely, we describe how facilitated system dynamics (SD), also known as group model building (GMB), can support the process of planning for resilience in SES and specifically in food systems. SD is a modelling methodology focused on understanding the circular relationships (feedback loops) driving the outcomes of the system (Richardson, 2011). SD focuses on endogenous behaviour, making this approach an excellent candidate for simulating a system's behaviour, for learning about the system's structure and outcome drivers, and for identifying key resources. In participatory settings, an SD model is not only a realistic representation of the system studied and its outcomes but is also a "socially constructed artefact" that helps stakeholders understand the system (Andersen, Vennix, Richardson, \& Rouwette, 2007, p. 692).

GMB is a "bundle of techniques used to construct SD models working directly with client groups on key strategic decisions" (Andersen et al., 2007, p. 691). The GMB intervention per se might end short of the construction of a full simulation model and focus instead on constructing diagrams that are used as social artefacts to facilitate discussion and knowledge creation (Zagonel, 2002, 2004). These diagrams are usually in the form of causal loop diagrams (CLDs) representing the variables, causal relationships and feedback loops of a system (Lane, 2008). In participatory settings, the modelling process turns into a discussion about the theories and hypotheses that explain the system's behaviour. The purpose of the discussion is not to predict behaviour but to gain an understanding about "what happens if?"

Our description and reflections are elaborated within the qualitative paradigm of case study research (Merriam, 2002; Stake, 1995) and are part of an independent model-based discussion of food security resilience to climate change in Guatemala. The purpose of the discussion is to yield practical insights about how to systemically prevent starvation and malnutrition among low-income households facing an increase in the frequency of droughts. With this purpose, different stakeholder groups (farmers, government representatives, and academics) actively 
collaborated through the GMB process to a) gain practical insights into the adaptive mechanisms of the food system at hand and b) identify ways to improve the resilience of food security.

While our results are exploratory, this case study illustrates how facilitated modelling helps participants carefully unfold the complexity of resilience and to dive into the underlying mechanisms that foster system adaptation. Facilitated modelling offers a road map for the resilience planning process, from defining what resilience means in the specific context to making an informed decision about systemic interventions to enhance it.

The paper proceeds as follow. First, there is a description of the steps proposed for using GMB and SD in the planning of resilience and how they fit within the framework proposed by Walker et al. (2002). Then, the same steps are carefully described within the context of the case study addressed in this paper. This case study description is next revised and complemented by feedback from the stakeholders participating in the process and our reflections and insights.

\section{A FACILITATED MODELLING APPROACH FOR RESILIENCE PLANNING IN SOCIO-ECOLOGICAL SYSTEMS}

We use the term "planning for resilience" (or resilience planning) to name the activities needed for analysing and managing a system so that its key outcomes are resilient to disturbances affecting the system. In simple terms, the goal of resilience planning is to prevent a system from moving to an undesired state by creating appropriate adaptation mechanisms within the system to prevent such a state. While resilience planning is embedded in the policymaking process, we do not use it in this context as a normative process. Alternatively, we propose using planning as a means for allowing stakeholders to co-discover how to adapt to and persist in the face of challenges in the environment (Holling \& Gunderson, 2002; Walker et al., 2002).

During the planning for the resilience process, it is important to address specific questions such as "resilience of what?" (Carpenter \& Gunderson, 2001), "resilience for whom?" (Cretney, 2014; Herrera, 2017b), "resilience to what?" and "what are the ways to build resilience?" (Walker et al., 2002). Consequently, the process is not a linear sequence of steps but a series of iterations between a) eliciting stakeholders' inputs regarding their knowledge about the system, their goals, values and needs and b)confronting them with quantitative data (historical or simulated by the model).

As a starting point for defining a facilitated approach for resilience planning, we used the working hypothesis of Walker et al. (2002) for a participatory approach to managing resilience. 
In our approach, we combine the steps outlined by Walker et al. (2002) to analyse resilience and standard steps of the SD modelling process (Sterman (2000)). To these steps proposed by Walker et al. (2002), we add a final step specifically focused on discussing policy implementation. The resulting process, as illustrated in Figure 1, consists of five steps: i) answering resilience of what?; ii) defining resilience to what? and developing scenarios; iii) developing a model and analysis; iv) identifying policy alternatives; and v) enacting policy implementation and management. Each of these steps is briefly described next.

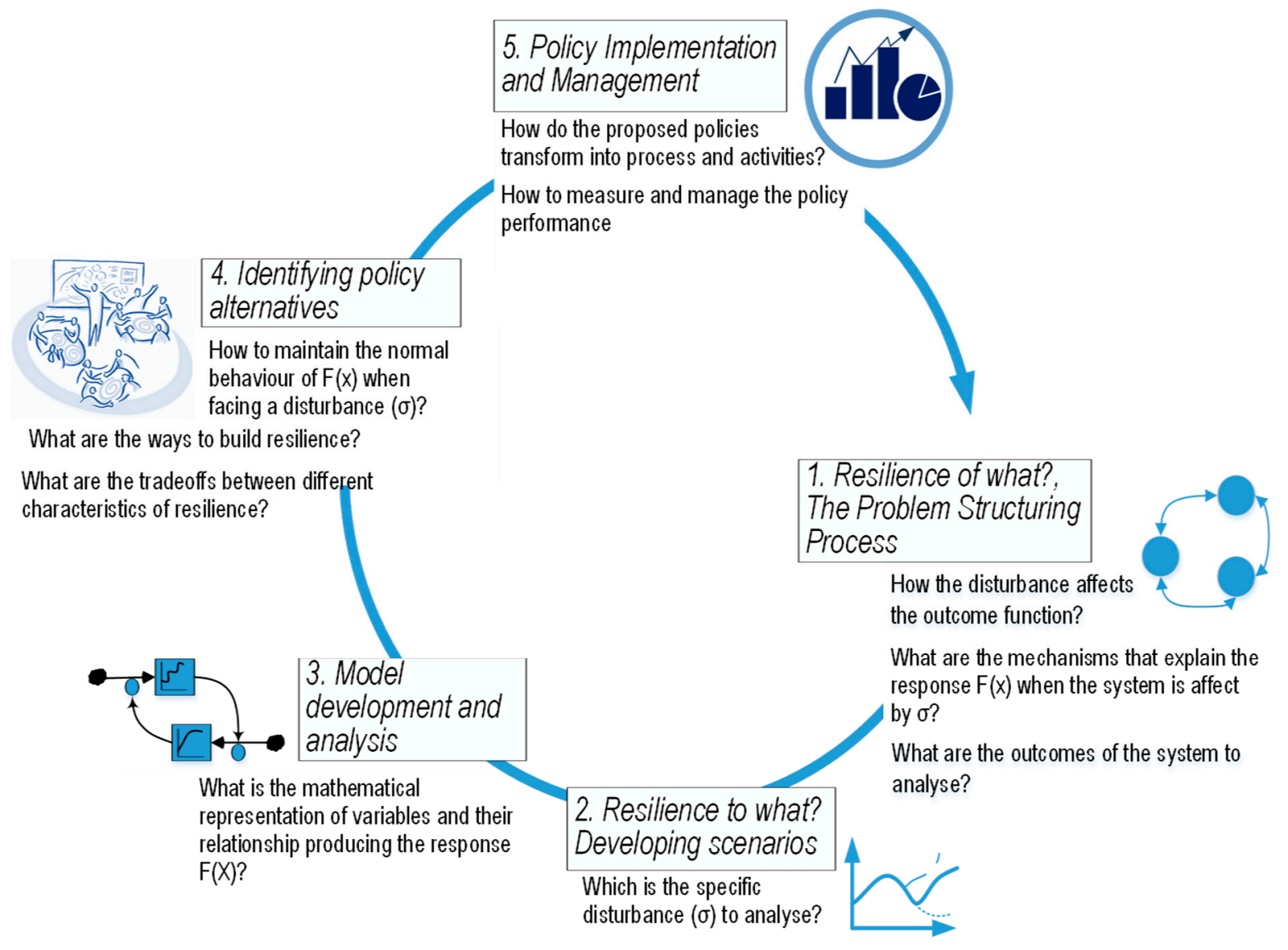

Figure 1: System dynamics modelling process tailored to the analysis of resilience. Adapted from (Herrera, 2017a)

\subsection{Resilience of what? The Problem Structuring Process}

Walker et al. (2002) state that the first step in the process is to develop a "conceptual model of the SES, based strongly on stakeholder inputs". The complexity and contentiousness of resilience imply that definitions of the problem and the system cannot assumed but need to be jointly constructed by stakeholders during a problem structuring process (PSP) (Herrera, 2017b). Since the concept of resilience is flexible and open to interpretation (Duit, 2015; Tendall et al., 2015), it is important to first agree on its interpretation during the scoping of the 
analysis. Without an explicit discussion and agreement about what outcomes need to be resilient, stakeholders risk talking past each other during subsequent stages of the problem. The purpose of the PSP is to a) conceptualise the analysis regarding the resilience of what? and b) to agree on a causal explanation -dynamic hypothesis (J. D. Sterman, 2000) - of the mechanisms supporting the resilience of the system outcomes.

We propose using GMB as a participatory approach to facilitate the PSP. GMB is a good environment for producing what Walker et al. $(2002,14)$ describe as a "conceptual model embodying what is known about the system regarding issues deemed important to the stakeholders, and what determines them". During the PSP, a GMB workshop offers a suitable setting for eliciting stakeholders' goals, fears and understanding of the system (Stave et al., 2017). To generate these settings, the GMB process uses a neutral facilitator to help moderate the process. It also uses a diagram, or a map, that participants can use to discuss their mentalmodels (implicit understanding) about resilience and the system. By encouraging the participants to represent their assumptions and knowledge in the diagram, they make these mental-models explicit. Since the explicit knowledge represented in the diagram can be shared, revised and integrated with other types of knowledge (e.g., hard data), it is expected that participants will learn from each other and develop a more robust understanding of the system and resilience in their own context.

\subsection{Resilience to what? Developing scenarios}

In the second step, Walker et al. (2002) propose focusing on "resilience to what?" This step concerns the analyses the external disturbance to which the system is expected to be resilient. The purpose of this step is to develop a set of plausible scenarios, that is, plausible alternative futures for a system based on different assumptions about what might happen in the future (Mahmoud et al., 2009). In this context, scenarios aim to capture not only the potential behaviour of external disturbances but also the expectations stakeholders might have about the system in general (Walker et al., 2002).

While scenario analysis has become popular in resource management literature (König et al., 2012; Mahmoud et al., 2009; Swart, Raskin, \& Robinson, 2004) there is no single method for performing it. There is, however, some agreement that the development of scenarios involves discussions between experts and stakeholders who work together to create a narrative of the future (Mahmoud et al., 2009). 
A usual way to elicit scenarios in the GMB workshops is to use graphs-over-time (Randers, 1980). The purpose of the graphs-over-time exercise is to elicit some critical outcomes and performance drivers that will reflect the system performance over a precise time horizon (Andersen \& Richardson, 1997). In the case of the analysis of resilience, the exercise can be used to ask the group participating in the workshop to draw the behaviour of a) external variables that might affect the system in a given time (disturbances) and b) key drivers and outcomes that might be affected by these disturbances. For instance, the facilitator might ask the participants about their belief about the future behaviour of rain, plagues, floods or other disruptive events and the expected behaviour of drivers and outcomes such as food production, land usage, food availability or food prices. The expected compatible behaviours drawn by participants are grouped into scenarios and are linked by narratives that describe a potential path for the future of the system.

The scenario narratives are important counterparts of a quantitative model, as they provide a perspective of critical social factors shaping the development of the system, "such as values, behaviours and institutions" (Swart et al., 2004, p. 140). Scenarios also offer an opportunity to explore transformation and how the system might transform as a result of disturbances pushing its nature beyond its limits (Walker et al., 2004, 2002a).

\subsection{Model development and analysis}

The third steps of the approach consist of assessing the interaction of the system defined in Step 1 in the scenarios defined in Step 2. The assessment of this interaction is not straightforward. Complexity and time delays between cause and effect make it difficult for decision-makers to anticipate what might be the effect of a disturbance in relevant outcomes of the system. Simulation models help mitigate this problem by simulating the behaviour of complex systems and their feedback relationships.

In this context, we propose building the SD models based on the stakeholders' inputs gathered during Steps 1 and 2 and supported with historical data and theories available in the literature about the system. The model might be built partially behind the scenes, but it needs to be validated, fully understood and accepted by the stakeholders participating in the process. The purpose of the model is to offer a simplified but realistic representation of the system and its behaviour when facing external disturbances. Once there is sufficient confidence in the model, it can be used as an aid for identifying "thresholds, their nature, and what determines their positions along the driving variables" (Walker et al., 2002b, p. 14). 


\subsection{Identifying policy alternatives}

The next step in the analysis process is to identify policy alternatives or potential interventions that might enhance the resilience of the desired outcomes of the system to the prioritised disturbances (for the stakeholders involved) (Walker et al., 2002). We propose using the model as a virtual laboratory for testing different policies or changes in the system and to identify points or areas for intervention (Sterman, 2000). Once again, this step in the process should not be mistaken for a predictive or optimisation exercise. This step is not an attempt to identify an optimal solution but is a discussion about the rules (incentives and disincentives) that enhance the system's ability to reorganise and move within some configuration of acceptable states (Walker et al., 2002, p.14).

However, a severe difficulty in analysing and comparing alternatives to build resilience is the lack of operational measures for resilience. While resilience can be, to some extent, inferred from system proxies or the behaviour of the system, observing qualitative behaviour is not enough. When comparing different policies, it is difficult to assess their effectiveness without a quantitative indication of their contributions to resilience or a reference of how resilient the system was before the intervention. In this paper, we used the set of resilience characteristics identified by (Herrera, 2017a). This set of measures, presented in Table 1, is defined to evaluate the resilience of outcomes in SD models and to offer an effective way to compare different alternatives. It is important to highlight that there might be trade-offs among the various characteristics of resilience, and hence, it is not possible to consider them in isolation.

\subsection{Policy implementation and management}

The final step proposed is to discuss how to transform the proposed policies into implementable projects. Implementation is often one of the most cumbersome aspects of resilience (Duit, 2015). Although some practical insights can be gained using models, the often-abstract nature of the analysis means that these insights still need refinement before being implementable.

Acknowledging this shortcoming, we propose to translate insights from the model into dynamic performance management (DPM) systems that allow policymakers, particularly in the public sector, to link the model insights with concrete activities and measurable outcomes. DPM is an approach for framing the causal mechanisms underlying performance in policymaking settings by combining SD and concepts from performance management (Bianchi, 2016) 
The process itself consists of identifying in the model the strategic resources (slow variables that influence the performance of the system), performance drivers (parts of the system that can be influenced) and performance outcomes (measurable outcomes that reflect the status of the system) related to each policy (Bianchi, 2016). Then, this network of strategic resources and performance drivers and outcomes are linked to a) activities and processes in the government system and b) broader goals and indicators. The result is a map that helps policymakers navigate from real processes (objective view) and feedback loop relationships (instrumental view) to high-level goals (subjective view) (Cosenz, 2014). Details about how to outline a DPM system in resilience planning are given in (Herrera, 2017c).

The aim of this step is twofold. First, it helps identify the challenges of implementing the proposed policies. For instance, what resources are needed?, which department will be responsible for what?, what are the links to existent processes?. Simultaneously, it smoothes the implementation by describing concrete performance measures that can be used to assess the realisation of benefits.

\section{MODEL-BASED DISCUSSION OF FOOD SECURITY RESILIENCE IN GUATEMALA}

Guatemala, like other developing countries, faces food security challenges that will only increase as climate change continues to affect small-scale farmers' capabilities to produce food. Guatemala's chronic malnutrition, an accepted measure of food insecurity, is the fourth worst in the world (World Food Programme, 2016), reaching 55\% in rural areas (Guardiola, Gonzáles, \& Vivero, 2006; World Bank, 2003). Climate change effects, such as severe droughts and increases in average temperatures already compromise the food production in Guatemala, especially among small-scale farmers (Bouroncle et al., 2015). Relying on agriculture as its primary economic activity, comprising $26 \%$ of its GDP, Guatemala's vulnerability to climate change poses a high risk to its economic and social activities.

Recognising this as problematic, studies that explore potential means to mitigate climate change effects have separately been commenced by scientists, NGOs and the government (see for example FAO, 2016; WFP, 2016). This research is part of these initiatives. It was independently conducted by the authors with the cooperation of numerous stakeholders in the dry region of the country. The purpose of the study was twofold. First, it aimed to yield practical insights about potential policies for increasing the resilience of food security in the region. Second, the study was a pilot test for the analytical method proposed in this paper. 
Prior to starting the process, with the help of local researchers and practitioners, we identified stakeholder groups that could potentially participate in the study. The groups identified were ranked according to their interest and their degree of influence in the decision-making process (see Figure 2). Regarding time and logistic constraints, of the groups identified, only those with high interest in the problem (stakeholders in quadrants 1 and 2) in Figure 2 were invited to participate in the formal process. These groups were: (a) the Central Government, (b) Jutiapa's Local Government, (c) small-scale farmers and their households and (d) academics.

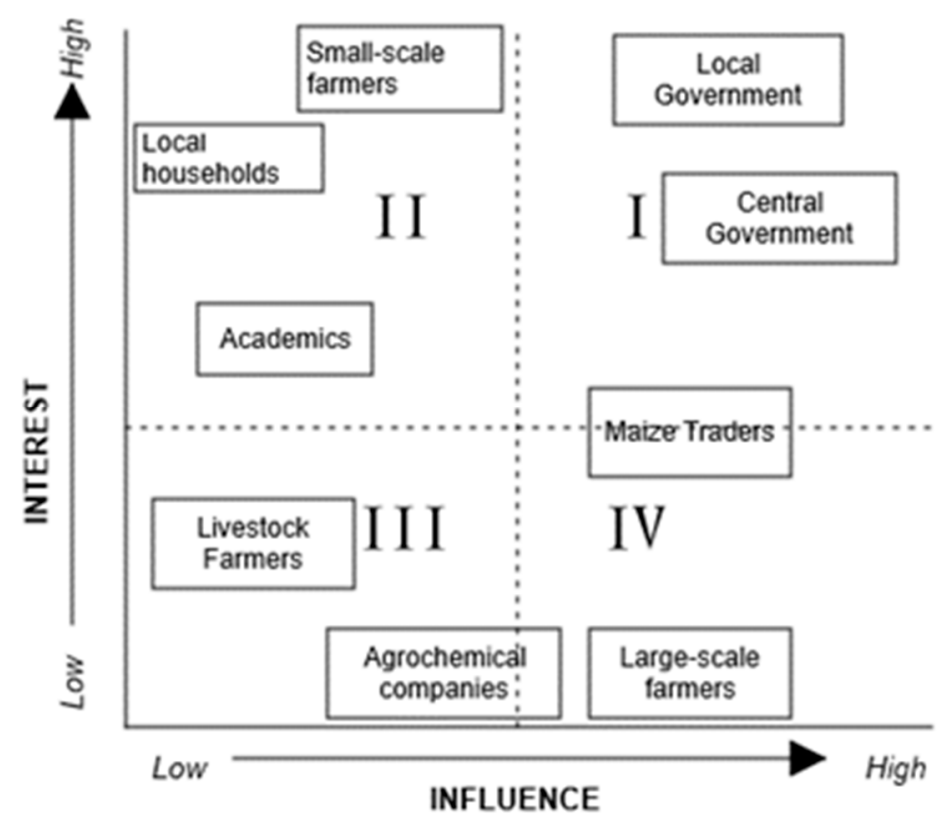

Figure 2. Stakeholder influence interest grid for stakeholders in Jutiapa's small-scale maize system. Table 2 offers an overview of the steps followed during this process and described in Section 2. Next, we briefly describe each step as conducted for this specific case. Since the purpose of this paper is to offer a replicable approach, we focus our description on the process while presenting tangible and intangible outcomes only to a level of detail needed to understand the benefits and limitations of it. We recognise that a detailed analysis of the discussions that took place during the workshop and the simulation results discussed can yield interesting insights about small-scale farming, food security and climate change adaptation. However, this detailed analysis is outside the scope of this paper. 
Table 2. Overview of the steps followed during the model-based analysis process of resilience.

\begin{tabular}{|c|c|c|c|c|c|}
\hline Step & $\begin{array}{l}\text { STEP } 1 \\
\text { Resilience to What? } \\
\text { The Problem } \\
\text { Structuring Process }\end{array}$ & $\begin{array}{l}\text { STEP } 2 \\
\text { Resilience to what? } \\
\text { Vision and scenarios }\end{array}$ & $\begin{array}{l}\text { STEP } 3 \\
\text { Model development } \\
\text { analysis }\end{array}$ & $\begin{array}{l}\text { STEP } 4 \\
\text { Policy alternatives }\end{array}$ & $\begin{array}{l}\text { STEP } 5 \\
\text { Policy management } \\
\text { and implications }\end{array}$ \\
\hline Purpose & $\begin{array}{l}\text { To define what resilience } \\
\text { means in operational } \\
\text { terms. Answer the } \\
\text { question resilience of } \\
\text { what? }\end{array}$ & $\begin{array}{l}\text { To identify what } \\
\text { disturbance might } \\
\text { disrupt or diminish the } \\
\text { desired outcomes of the } \\
\text { system (aka food } \\
\text { security) }\end{array}$ & $\begin{array}{l}\text { To produce a simulation } \\
\text { model to analyse the } \\
\text { system dynamics and } \\
\text { identify thresholds, their } \\
\text { nature, and potential } \\
\text { leverage points. }\end{array}$ & $\begin{array}{l}\text { To discuss potential } \\
\text { policies or interventions } \\
\text { in the system that might } \\
\text { enhance the resilience of } \\
\text { its outcomes. }\end{array}$ & $\begin{array}{l}\text { To identify and discuss } \\
\text { the implications and } \\
\text { challenges of } \\
\text { implementing the } \\
\text { proposed policies. }\end{array}$ \\
\hline $\begin{array}{l}\text { Concrete } \\
\text { activities }\end{array}$ & $\begin{array}{l}\text { Activities in GMB } \\
\text { workshop 1: } \\
\text { - Elicit variables } \\
\text { (resources and } \\
\text { drivers) } \\
\text { - Elicit causal links } \\
\text { among resources, } \\
\text { drivers and } \\
\text { outcomes of the } \\
\text { system. } \\
\text { Discuss how the } \\
\text { variables affect the } \\
\text { resilience of the } \\
\text { desired outcomes }\end{array}$ & $\begin{array}{l}\text { Identify disturbances } \\
\text { that might affect the } \\
\text { system. } \\
\text { Discuss scenarios } \\
\text { about the likelihood, } \\
\text { magnitude and } \\
\text { potential impacts of } \\
\text { the identified } \\
\text { disturbances in the } \\
\text { system. }\end{array}$ & $\begin{array}{l}\text { Validate model and } \\
\text { document its caveats, } \\
\text { limitations and purpose. }\end{array}$ & $\begin{array}{l}\text { Activities distributed in } \\
\text { two GMB workshops } \\
\text { (GMB workshops } 2 \text { and } \\
\text { 3): } \\
\text { - } \quad \text { Identify policy } \\
\text { alternatives. } \\
\text { - Discuss simulation } \\
\text { results of } \\
\text { alternatives } \\
\text { proposed. } \\
\text { Discuss broader } \\
\text { implications of } \\
\text { policies proposed } \\
\text { and trade-offs in } \\
\text { other parts of the } \\
\text { system. }\end{array}$ & $\begin{array}{l}\text { Develop a performance } \\
\text { management system. } \\
\text { - Translate the model } \\
\text { into an } \\
\text { "instrumental" view } \\
\text { of the system } \\
\text { - Discuss activities } \\
\text { and process needed } \\
\text { to implement the } \\
\text { proposed policies. } \\
\text { - Identify key } \\
\text { performance } \\
\text { indicators. }\end{array}$ \\
\hline $\begin{array}{l}\text { Tangible } \\
\text { outcomes }\end{array}$ & $\begin{array}{l}\text { Causal loop diagram } \\
\text { describing how } \\
\text { resilience "works". }\end{array}$ & $\begin{array}{l}\text { Graphs-over-time } \\
\text { Scenarios }\end{array}$ & $\begin{array}{l}\text { Simulation System } \\
\text { Dynamics Model }\end{array}$ & $\begin{array}{l}\text { Multicriteria policy } \\
\text { assessment }\end{array}$ & $\begin{array}{l}\text { Framework for a } \\
\text { performance } \\
\text { management system }\end{array}$ \\
\hline
\end{tabular}




\subsection{Resilience of what?}

Prior to the GMB workshop, we conducted a one-to-one session to set the scene, introduce delegates to the issue and gather information regarding different goals for the system, different understandings of resilience for their context and their initial understanding of how the system works. The interviews were followed by a three-hour GMB workshop to discuss food security resilience to climate change. Namely, participants discussed the reasons for the recent decrease (see Figure 3) in food security measured by using the proxy of average kilocalories (kcal) consumed per person per day (Vhurumuku, 2014).

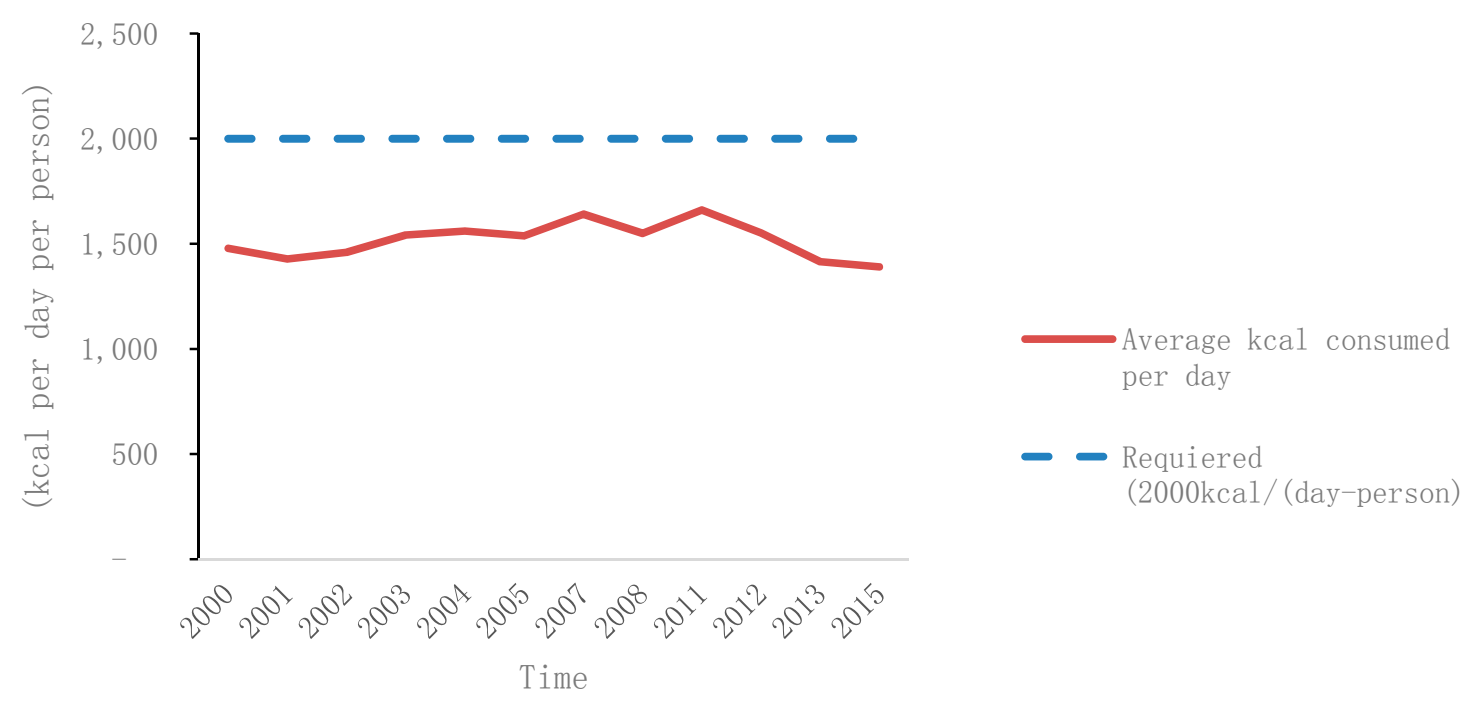

Figure 3: Historical behaviour of kcal consumed per capita per day in Jutiapa, Guatemala. Source: SEGEPLAN (2016)

The workshops were facilitated by the first author, and they broadly followed scripts widely used in GMB workshops and described by Andersen \& Richardson (1997). The workshop started with a round of introductions, presentations of the objectives for the workshop and the overall agenda. As part of the introduction, participants were asked to briefly explain what needed to be resilient and what they understood by resilience.

Next, the facilitator asked participants about the three primary outcomes of the system to achieve food security resilience. The outcomes were captured in the form of variables in a flipchart visible to the whole group. Then, the facilitator led the process of connecting the variables produced in the previous step by linking causes and effects with arrows. The purpose of this step was to use variables proposed by the group to "build an explanation of how climate change affects food security in this case". When needed, participants suggested adding intermediate variables for linking different outcomes. Once most of the variables were interconnected, the participants were asked to describe how different strategic resources were 
connected to each other and were encouraged to find circular causal relationships (feedback loops).

The tangible outcome of the process described above was a causal loop diagram (CLD) explaining the ways climate change affects the food security of small-scale farmers at a local level. CLDs are diagrams used to capture a broad representation of the causal relationships and feedback loops in a system (Lane, 2008). Causal relationships are represented by arrows connecting the cause with its effects. The "polarity" or nature of the causal relationship is represented by a plus (+), if the cause and effect "move" in the same direction, or a minus (-), if they "move" in opposite directions (Lane, 2008). Similarly, the polarity of the loops is identified by letters, an ' $R$ ' in the case of reinforcing or self-compounding loops and a ' $B$ ' in the case of balancing or constraining ones.

The causal relationships discussed and represented in the CLD were used to explain how climate change will affect the system and to answer the question "resilience to what?". The CLD contains the agreed upon dynamic hypothesis or causal explanation of how the system works and how it reacts, in a structural way, to climate change. This explanation is captured in the CLD presented in Figure 4 and constitutes the initial conceptual model of the system. The thick lines in the figure highlight the main feedback loops discussed during the workshop. 


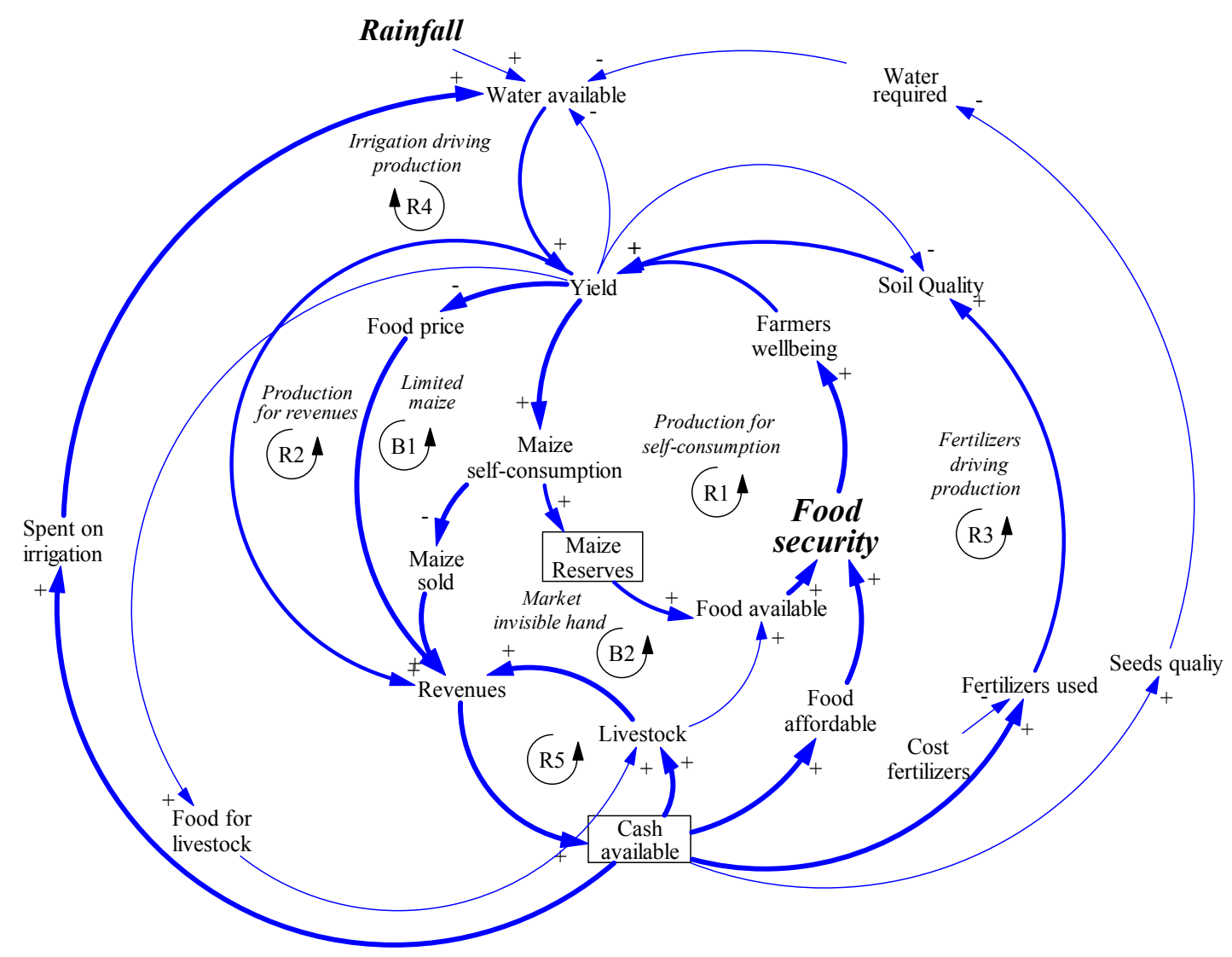

Figure 4: Causal loop diagram created by delegates from stakeholders during the group model building workshop

Note: a plus (+) indicates that cause and effect "move" in the same direction, and a minus (-) indicates that they "move" in opposite directions (Lane, 2008). The polarity of the loops is identified by letters,

an ' $R$ ' in the case of reinforcing or self-compounding loops and a ' $B$ ' in the case of balancing or constraining ones.

The resilience of food security was understood by the group as depending on two main feedback loops: production for self-consumption (R1) and production for revenue (R2), as shown in Figure 4. Production for self-consumption describes food security as dependent on how much of the maize produced can be allocated for self-consumption (see R1 in Figure 4). It is important to keep in mind that in rural areas of Guatemala, maize contributes up to $60 \%$ of the total calories ingested per person (Fuentes, 2002). Hence, allocating part of the production to self-consumption and being able to build reserves are essential ingredients of resilience and are critical conditions for withstanding variations in the harvests.

Food security also depends on how much food farmers can afford, meaning how much cash they have available for buying food. With a family economy based on the production of maize, cash depends almost entirely on the revenues from maize production. The relationship between revenues and food security is described by the feedback loop production for revenues (R2) in Figure 4. 
These two loops (R1 and R2) highlight the importance of two key strategic resources in the resilience of the system: cash available and food reserve (see rectangles in Figure 4). These two strategic resources act as buffers during times when the yields are low, and they help farmers minimise the effect of a bad year in their food security.

Other important feedback loops to consider are those describing alternative mechanisms that (according to the participants in the workshop) might help boost the two key strategic resources identified above. The feedback loop fertilizers driving production (R3 in Figure 4) and irrigation driving production (R4) describe how cash available can be used to improve production by obtaining a) more fertiliser and b) better irrigation systems. Higher production might translate into higher revenues that eventually increase the cash available for investing in more fertiliser or better irrigation. To a minor extent, cash also depends on the feedback loop livestock production (R5 in Figure 4). More cash available means farmers can acquire and maintain more livestock (commonly poultry), which represents an additional source of revenue and food.

The group also identified two significant constraints for building resilience captured in two balancing loops in Figure 4. First, there is a limited amount of maize that can be produced, so farmers need to decide whether to save maize for self-consumption or to sell it in the market. The constraint on the maize produced is captured in the feedback loop limited maize (B1 in Figure 4). Second, and related to the previous loop, if more maize is made available to the market, the price decreases and the increase in revenue might be more modest than expected or even negligible. The dynamic between supply and demand is represented by the feedback loop invisible market hand (B2 in Figure 4).

\subsection{Resilience to what? Vision and scenarios}

During the same GMB workshop 1, the facilitator asked the participants to draw graphs-overtime of the expected behaviour of food security and the drivers and outcomes contributing to it. Namely, participants were asked to pick some of these outcomes and drivers and to draw what they thought was the historical behaviour of these variables. Once they had drawn past behaviours for a small group of variables, the facilitator asked them to add to the same graph the trends they expected in the medium-term. When participants added trends to all the graphs, they were asked to add a line representing the type of future behaviour that would be preferable for each of the variables. An example of the graphs-over-time is shown in Figure 5. 

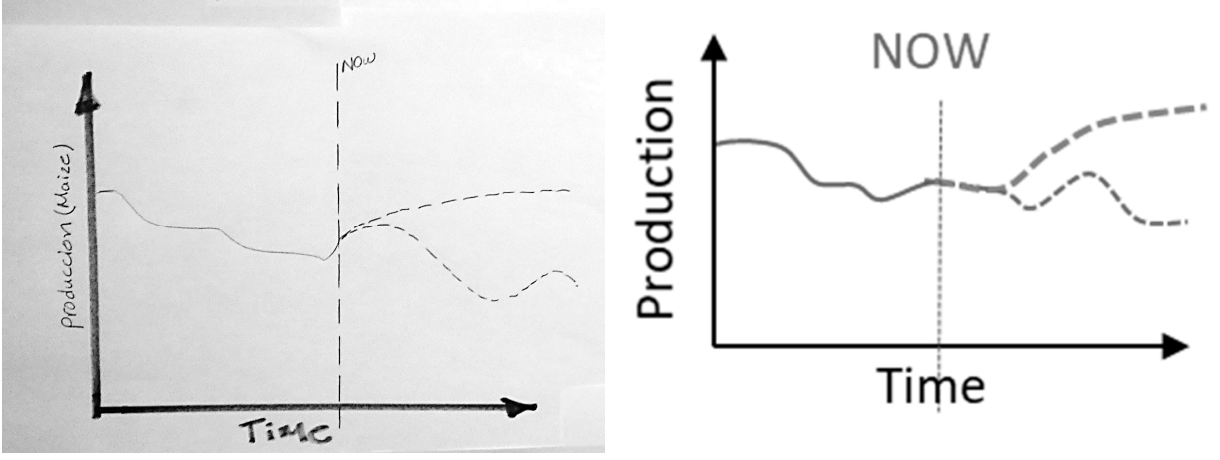

Figure 5. a) Picture and b) stylized representation of one of the graphs-over-time produced by the participants during the workshop.

The graphs-over-time were used during the same workshop to describe potential scenarios for the food security of small-scale farmers in the region. The facilitator asked the participants to work in small groups and to describe which disturbance or shock they thought might be responsible for the undesirable trends represented before. In case the disturbance was not already among the drivers for which the participants had drawn a graph-over-time, they were free to draw a new one. After identifying potential disturbances, each group was asked to describe how those disturbances will affect other drivers and the outcomes contributing to food security. To indicate the links between disturbances and outcomes, participants connected graphs-over-time using arrows (see Figure 6). While doing so, the facilitator encourages participants to explain and discuss with others the meaning of each arrow. When the participants concluded the exercise, they presented their diagrams and used them to describe the scenario they had constructed, explaining how a disturbance will affect the future behaviour of the system.

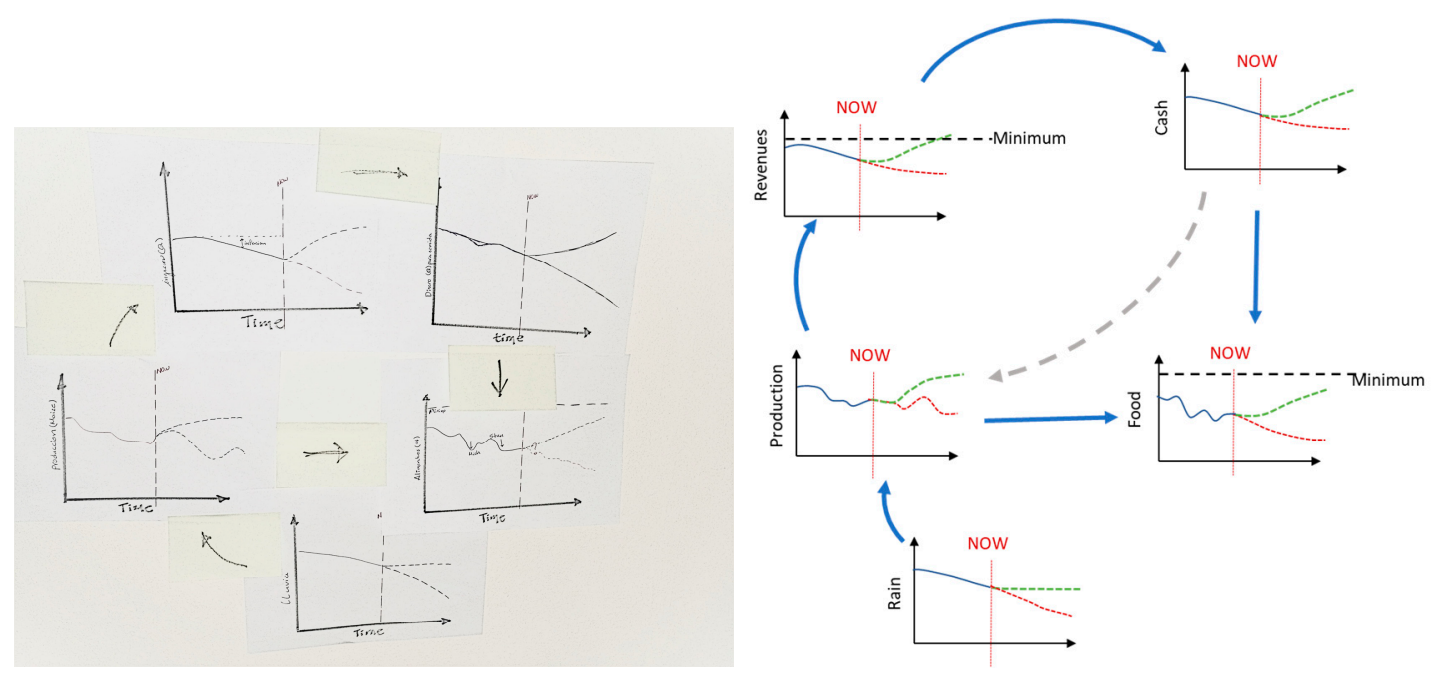

Figure 6: Example of the graphs-over-time prepared by the participants. 
The scenarios outlined three potential development paths for the system. One alternative, outlined in the Scenario 1, is that the changes in climate conditions have already happened (see Figure 7). If the climate has already changed, from now on, the amount of rainfall will be less than before, but it will not continue to decrease. In this scenario, the farmers think that with government assistance in investing in irrigation systems, they could reorganise their farms and eventually go back to their previous productivities.

Alternatively, Scenario 2 describes a path in which rainfall will continue decreasing, thus increasing the severity of droughts in the region. This scenario would be incredibly challenging for farmers because maize is a water-intensive crop that requires much water to reach high yields (see Figure 7). This is a kind of "doomsday" scenario, and farmers think such conditions will severely threaten their survival.

Finally, Scenario 3 describes a future in which weather conditions are continually changing: severe droughts might be expected, followed by periods with abundant rainfall (probably even floods). This scenario would be challenging because farmers might lose much cash during the bad years (see Figure 7). Planning for such variability was described as a challenge. Increase poverty levels during the bad years will prevent farmers from taking advantage of the good years when yields could be higher.

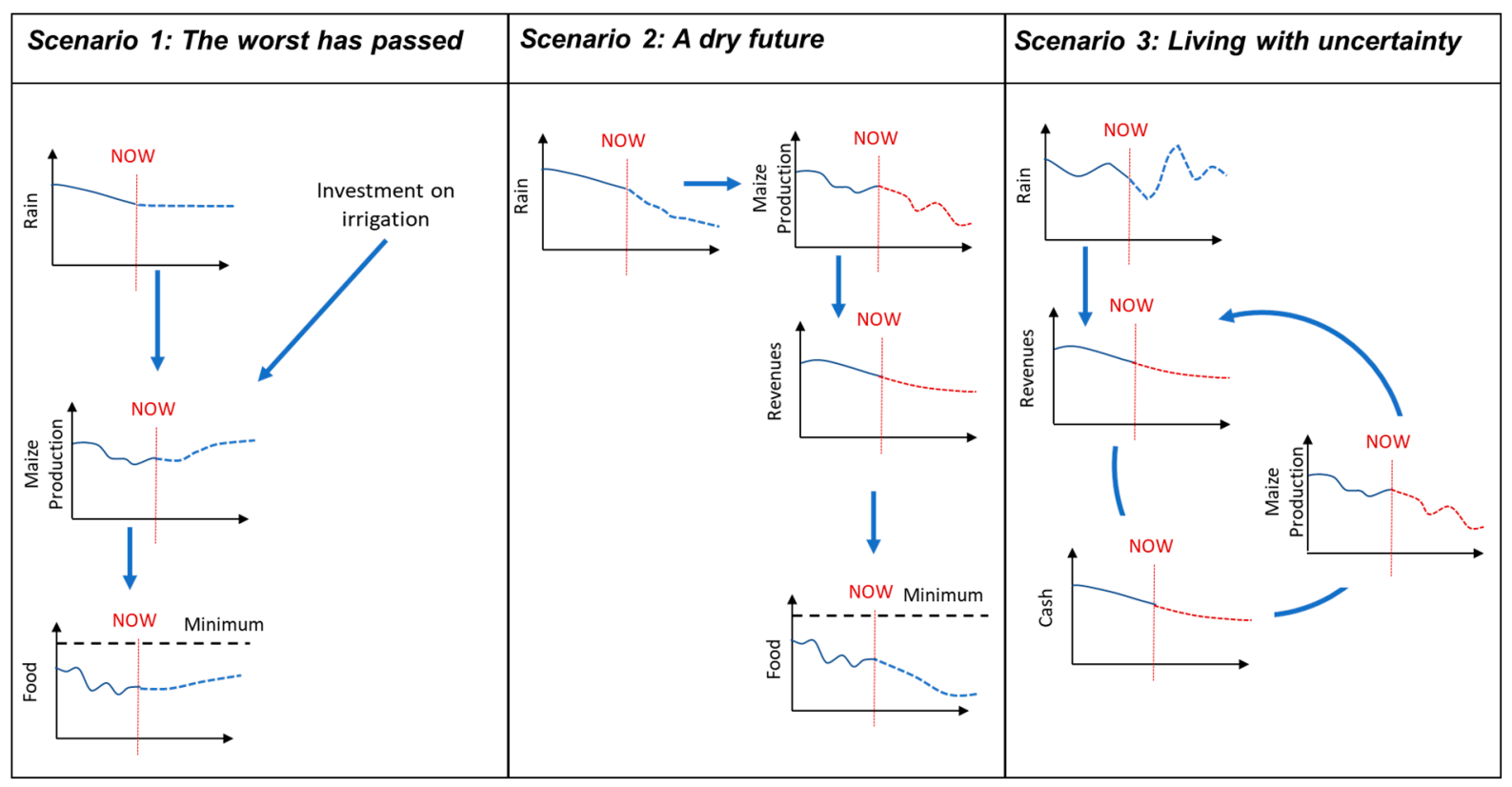

Figure 7: Scenarios developed during the GMB workshop using graphs-over-time. 


\subsection{Model development and analysis}

The SD model was built behind the scenes based on the inputs gathered during the first GMB workshop and was supported with statistical data and any literature available on the specific case of Jutiapa and small-scale farm systems in general. The model was built in Vensim DSS and was validated following good SD modelling practices (Barlas, 1996; Morecroft, 2015; J. D. Sterman, 2000). We devoted a considerable amount of time to working with the stakeholder delegates in one-to-one sessions to ensure the model was understood and that the relationships, data and principles included in the model were transparent. The purpose of these sessions was to discuss the following:

a) variables containing assumptions without underlying empirical information

b) simulation results produced and the causal loops producing them

c) results of sensitivity and stress tests performed in the model

The sessions also helped build confidence in the stakeholders that the model was fit for its purpose and that it appropriately represented the information available and their knowledge about the system. The exercise quickly turned into a learning process because the delegates learned about the system by reviewing and interrogating the model. At the same time, they helped to inform and refine the model with insights that were not mentioned during the GMB workshops. A detailed description of the model can be found in Appendix 2.

\subsection{Identifying policy alternatives}

Once the model was considered fit for its purpose by the modeller and the stakeholders involved, it was used to facilitate the discussion about potential policies to enhance the resilience of food security. The discussion was conducted through two GMB workshops (2 and 3) and was supported by work behind the scenes between the workshops.

GMB workshop 2 focused on identifying policy alternatives for enhancing the resilience of the food security of small-scale farmers. The workshop, facilitated by the first author, lasted 90 minutes and consisted of two main exercises. The first half of the workshop was used to experiment with the model and to assess the effect of changing the value of certain variables on the outcomes that contribute to food security (e.g., maize price and food affordability). Changes in the outcomes were observed over a ten-year period, extending the simulation horizon until 2025. Figure 8 shows some of the simulation results presented in the workshop. It shows the expected effect, everything else remaining the same, of reducing subsidies currently provided by the government for purchasing fertiliser on the calorie intake per capita. 
While there is a noticeable effect on food security, the effect found was not nearly what they expected. Counterintuitive results like these sparked excited discussions about the question "what is influencing food security?"

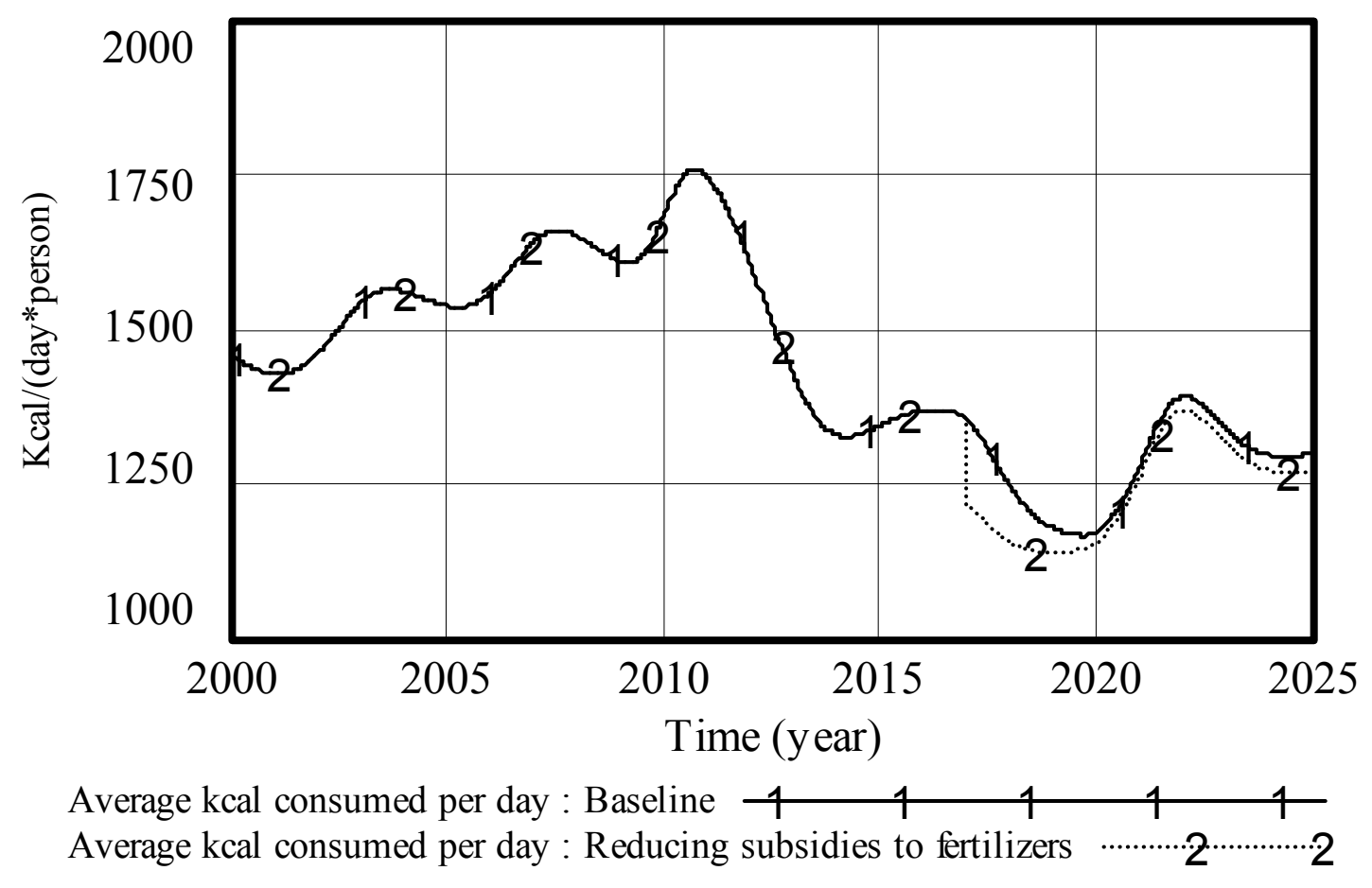

Figure 8: example of simulations run in the workshop to assess the effects of reducing fertiliser subsidies by $25 \%$ on food affordability

The second half of GMB workshop two was used to describe potential policy alternatives to enhance the resilience of food security. Participants worked in small groups for approximately 30 minutes, articulating what might be, based on their experience and the results observed in the model, the best way to enhance the resilience of food security. Then, each group briefly presented a policy they wanted to propose to the whole group. The workshop concluded by identifying a short list of three policies the stakeholders wanted to explore in detail:

1) Support households with direct revenues

2) Support the development of livestock resources

3) Increase subsidies for fertiliser

In-between the workshops and behind the scenes, the three policies proposed were added to the model. The results of introducing the different policies were assessed using simulations and were compared against the original results produced prior to introducing the policies. As described before, the impact of each policy regarding the resilience of food security was 
quantified using the five measures proposed by Herrera (2017a). More details about the way each measure is calculated from the simulation results can be found in Herrera (2017a).

Previous to GMB workshop 3, and as part of the behind the scenes work, the authors engaged with the delegates of the different stakeholder groups to discuss the measures used to assess resilience. The purpose of this engagement was to have sufficient time to explain the measures proposed and their meaning in real-world settings. Simple examples were used to illustrate what the specific measures meant and to improve the stakeholders' understanding of the meaning of each measure. For instance, low robustness was compared to the system being a "nervous chicken" moving all over the place in the presence of a disturbance. Alternatively, high robustness values were compared with a "bull", impassive to the changes of the environment.

GMB workshop three was conducted to discuss the policies proposed in the previous workshop and their implications for resilience. Like the previous workshop, it lasted 90 minutes and was facilitated by the first author. The workshop consisted of three parts. During the first part (lasting approximately 45 minutes), the authors presented the impact of the policies on food security resilience regarding the five measures of resilience. When participants had questions about the results or the reasons for a particular value, the facilitator referred back to the model and used simplified CLDs to explain the reasons underlying the results.

The simulation model allowed the participants to explore and to compare the impacts of different policies on the resilience of food security. Figure 9 shows the results for policies when the system is shocked by a severe drought, like that described above in Scenario 2. Figure 9 shows that food security behaves differently when different policies are in place. For instance, granting cash support to farmers (Policy 1) and increasing fertiliser subsidies (Policy 3) improve food security in Scenario 1, while increasing livestock (Policy 2) has almost no effect on the same conditions. 
Policy 1

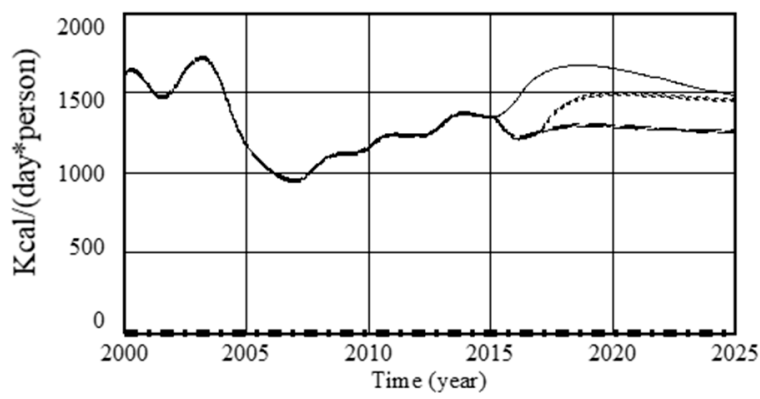

Policy 3

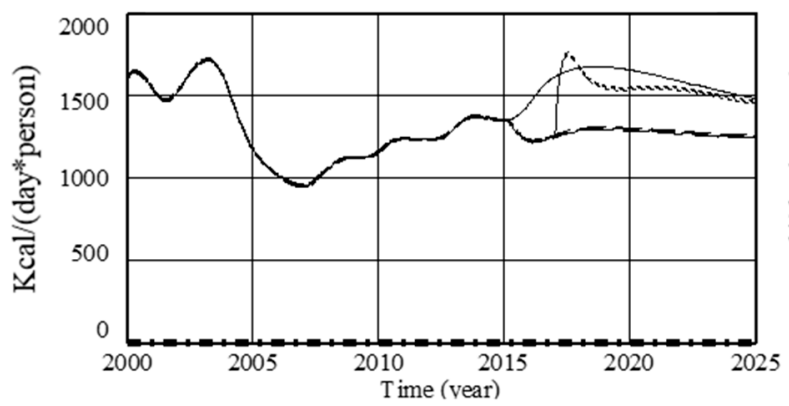

Policy 5

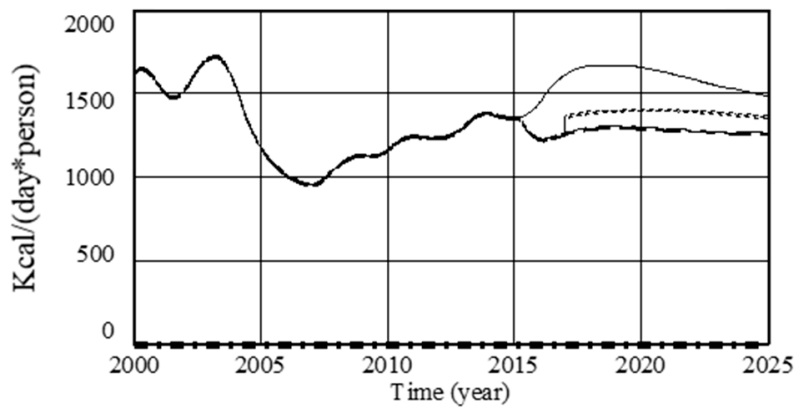

Policy 2

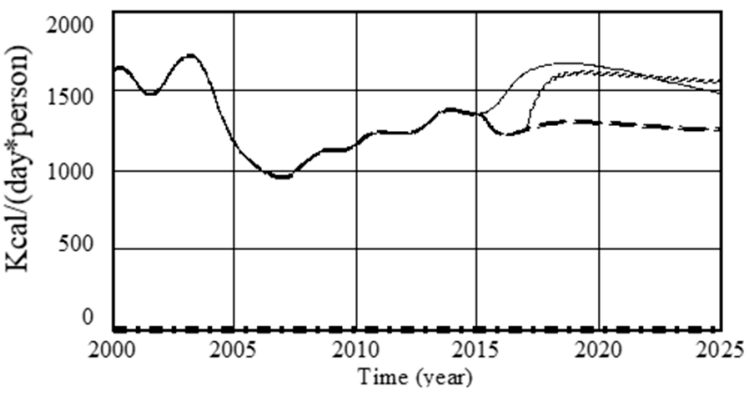

Policy 4

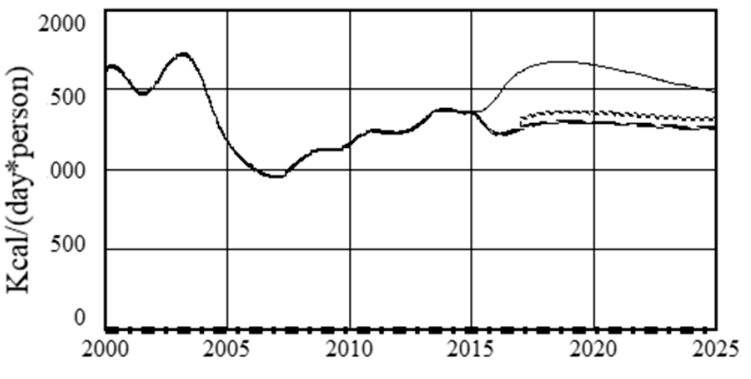

Baseline

Affected by a Disturbance

Affected by a Disturbance with Policy in place

Figure 9: Example of simulation results used during GMB workshop 3 to discuss the implications of the policies proposed. Increase fertiliser subsidies when the system is affected by an extreme drought, as described in Scenario 2 above.

Because it is difficult to compare the policies by merely looking at the simulated behaviour presented above in Figure 9, the results were further analysed and compared regarding the five measures described in Section 2 of this paper. The results show the impacts of the different policies for a range of rainfall amounts representing the three different scenarios proposed. For this purpose, Monte Carlo simulations were created in Vensim DSS. For more details about how to calculate the different measures using Monte Carlo simulations, please see Herrera (2017a). Table 3 shows the results of the three policies proposed. 
Table 3. Measures of resilience

\begin{tabular}{|c|c|c|c|c|c|}
\hline Measure & & Baseline & Policy 1 & Policy 2 & Policy 3 \\
\hline Hardness & (average $\%$ rainfall variation) & $4 \%$ & $12 \%$ & $9 \%$ & $5 \%$ \\
\hline $\begin{array}{l}\text { Recovery } \\
\text { speed }\end{array}$ & $\begin{array}{l}\text { ( } \triangle \% \text { diet requirements } \\
\text { met/year) }\end{array}$ & $0.3 \% /$ year & $0.6 \% /$ year & $0.5 \% /$ year & $0.3 \% /$ year \\
\hline Robustness & $\begin{array}{l}(\triangle \% \text { annual rainfall } \\
\text { variation } /(\triangle \% \text { diet } \\
\text { requirements met })\end{array}$ & .04 & .08 & .07 & .06 \\
\hline Elasticity & (average $\%$ rainfall variation) & $8 \%$ & $18 \%$ & $22 \%$ & $10 \%$ \\
\hline $\begin{array}{l}\text { Resilience } \\
\text { Index }\end{array}$ & $\begin{array}{l}\text { (\% Probability to maintain } \\
\text { regime) }\end{array}$ & .61 & .90 & .94 & .72 \\
\hline
\end{tabular}

Note: Policies tested are Policy 1: Support the households with direct revenues, b) Policy 2: Support the development of livestock resources and c) Policy 3: Increase fertiliser subsidies.

The second section of the workshop was a facilitated discussion about the broader implications of each policy. For instance, it was noticed that the increase in food security resilience in Policy 3 was overall associated with an increase in the amount of planted land. The limited access to land and the poor quality of the terrain were also discussed.

In the third and final section, the facilitator asked the participants to briefly enumerate the next steps to follow in the process to move the analysis into the planning phase. The list of activities proposed was shared with all the participants and can be picked up in subsequent projects.

\subsection{Policy implementation and management}

After GMB workshop three, the authors worked with representatives of the central and local governments, outlining DPM systems for each policy proposed. The creation of the diagrams combined work behind the scenes, with the first author drafting DPM maps, will small discussions with representatives from the government. The topics addressed during these discussions were the following:

a) what were the processes and activities needed to implement the policy?

b) how would these process fit in their current organisations and among other projects they currently have?

c) how could they measure progress and performance?

d) how will the proposed policies fit within the broader policy context? 
Figure 10 shows the dynamic performance management map drafted for Policy 2. The figure shows, at a very high level, the important activities needed for implementing the policy, estimates for the resources needed and the key performance indicators that can be used to measure the policy performance. 


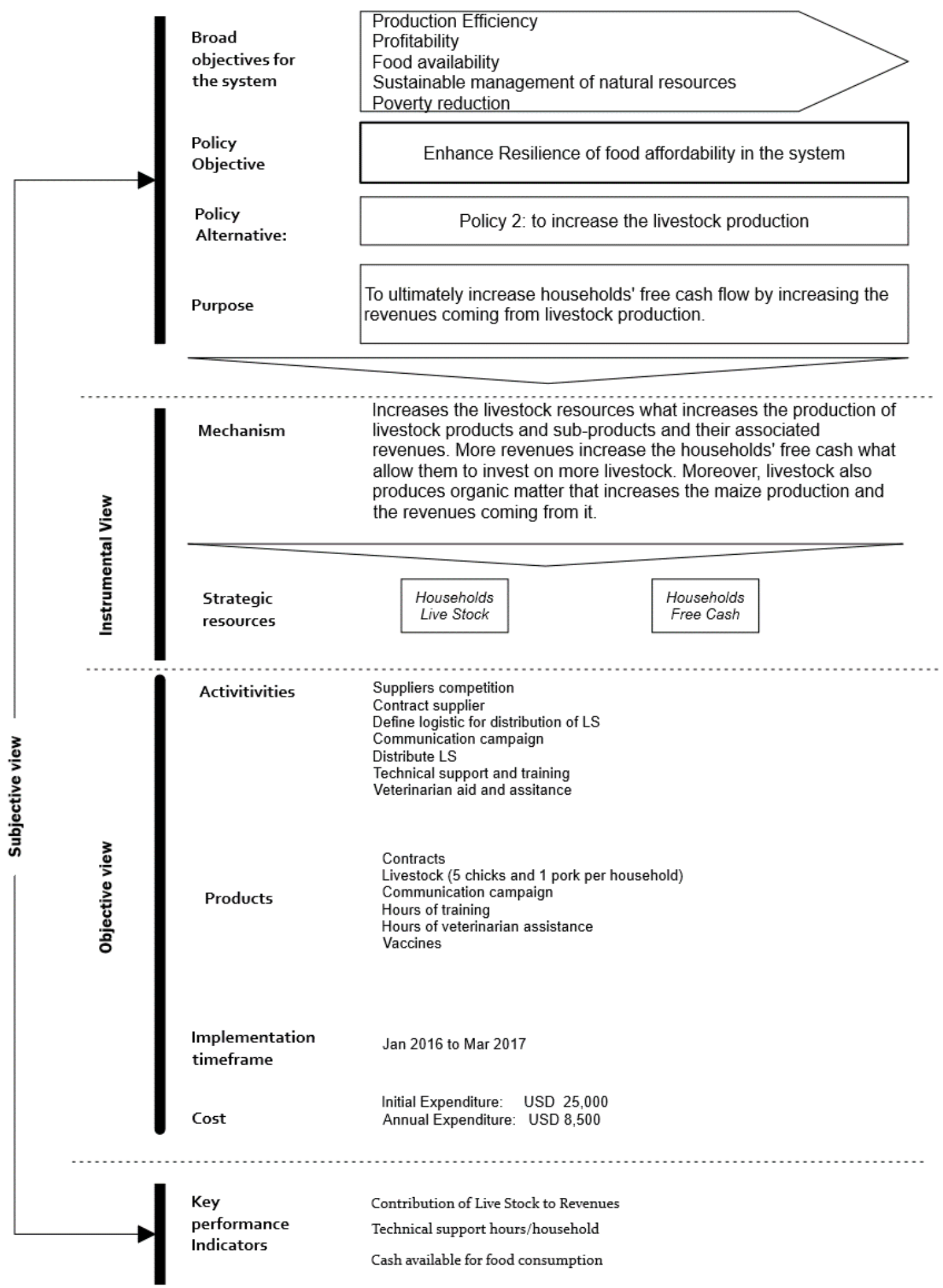

Figure 10: Dynamic Performance Map for Policy 2: Support the development of livestock resources 
The outcomes of this final step in the process are the basis for preparing concrete project proposals. Even the transition to the implementation stage is often taken for granted; it is important to recognise that implementation is not automatic. The insights gained during the analysis will need to be transformed into concrete and feasible projects before having any impact in the real world. The usefulness of having a DPM diagram such as the one in Figure 10 should not be underestimated.

Preparing the DPM diagram helped the policymakers understand the resources needed and the feasible timescales for implementation. Additionally, the process of building the DPM diagram helped identify additional constraints and potential complications in the implementation. For instance, in the case of Policy 2 (incentivise livestock), providing appropriate veterinary assistance to all the farmers will be nearly impossible due logistical constraints. The logistics needed pose a significant threat to the policy's success, since livestock will need vaccines that have to be kept refrigerated and must be managed and transported appropriately. Without vaccines, the livestock will be susceptible to diseases, jeopardising Policy 2 .

\section{INTANGIBLE OUTCOMES}

\subsection{A joint understanding of the system and resilience}

The approach proposed in this paper offers a formal framework for engaging with stakeholders and reaching some degree of consensus about what resilience means. The experience in Jutiapa shows that using facilitated modelling smoothed the discussion about the otherwise abstract description of resilience. In particular, building the CLD during GMB workshop one required that the participants a) make their assumptions explicit and b) discuss resilience regarding operational drivers and outcomes. By operationalising their assumptions into variables and links, the participants managed to reach some implicit level of consensus about the answers to questions such as i) what does resilience mean?, ii) what outcomes and drivers contribute to resilience? and iii) what are the boundaries of the system? The CLD and subsequent analysis reflect that to some extent, participants managed to agree on these fundamental questions while still having different opinions about what is the best policy for enhancing resilience.

Simultaneously, the inclusion of stakeholders resulted in a broader description of the system and a more robust representation of how the system works. We hypothesised that the number of feedback loops and the richness of the analysis would probably have been impossible without involving a diverse group. This hypothesis is supported by the participants' feedback regarding how the process helped them broaden their perspectives. 
"It helped us see the complexity of the farmers' problem. It is not only about adding here or there but about how to make it work" (Delegate from Central Government) "I did not know how important the food reserves are for the farmers" (Delegate from Local Government)

"The problem is complex, there are many ways to solve it, and we need to work together more" (Delegate from Central Government)

Having a more comprehensive and more diverse understanding of the system and its potential developments is helpful in dealing with uncertainty and the always-limited understanding of SESs. By including different perspectives in the causal loop diagram, it is possible to capture relationships and feedback loops that otherwise would have been disregarded. These allow a more comprehensive model of the system that can better represent alternative and unexpected development paths for the system.

\subsection{A more robust understanding of key resources contributing to food security resilience}

A fundamental purpose of resilience planning is to gain a more robust understanding of the key adaptation mechanisms in the system (Biggs et al., 2012). However, complex systems are cumbersome without the aid of simulations (Diehl \& Sterman, 1995; Richardson, 1986; J. Sterman \& Sweeney, 2002). Our experience in Jutiapa shows that a qualitative analysis might fail to identify critical strategic resources or might overestimate the impact of certain drivers on the outcomes of the system. For instance, the qualitative analysis undertaken during GMB workshop 1 using the CLD identified two key strategic resources: cash available and maize reserves. The importance of livestock became apparent only after running the simulation results and exploring Policy 2.

Participants also gained insights into the mechanisms driving the system's behaviour. At the beginning of the process, many of the stakeholders believed that revenues alone drove the system. This hypothesis was refined during the process as the other mechanisms in the system became more important to explain the simulated behaviour. The diagram in Figure 11 illustrates one of these mechanisms driving resilience that became obvious during the analysis. When rainfall decreases, less water is available for consumption. Less water has a direct impact on the amount of maize produced. A reduction in the maize produced diminishes the returns farmers will obtain from the cash they have invested in the process, reducing the cash available and simultaneously diminishing the farmers' ability to buy food and invest in the next harvest. 


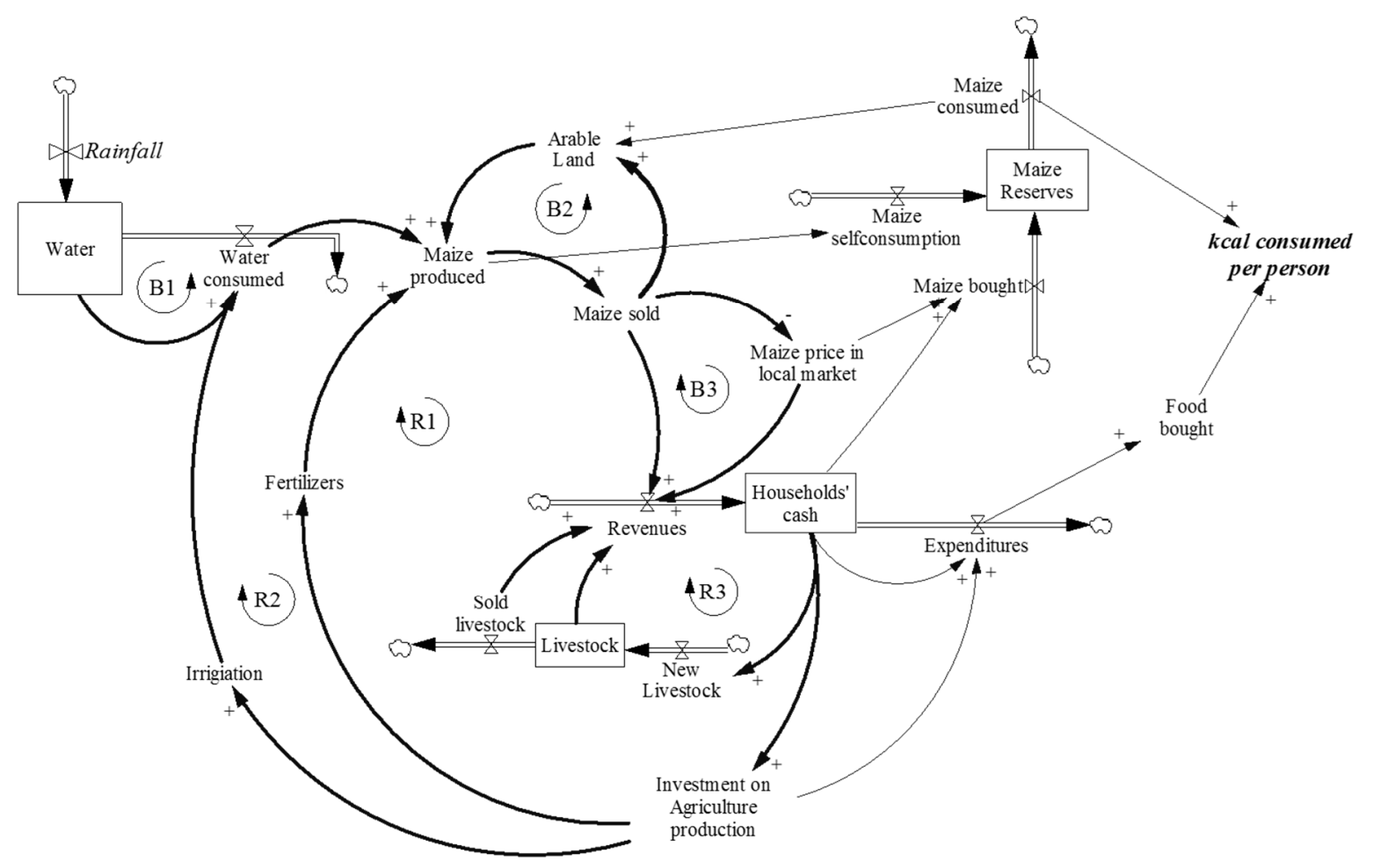

Figure 11: Aggregated representation of the model

For farmers, it is difficult to decide where to invest: in future harvests or food today? On the one hand, investing in future harvests compromises their subsistence and wellbeing without the certainty of producing sufficient yields in the future. On the other hand, if farmers only invest in food for the season, they are cut off from their primary source of revenue for the next year.

The implications of this investment decision concern not only the farmers but also the whole community. Since local production is cheaper than maize in the broad market, local households often prefer maize produced by neighbours than maize from other regions. A temporary reduction in cultivated land and reductions in the investment in agriculture supplies have small effects on the supply of maize. These effects are eventually compensated for by the prices in the market. However, if the loss in the harvest is too significant, farmers might be unable, without external help, to restart the production cycle. An extreme loss in the harvest could be expected in Scenarios 2 and 3, and with farmers unable to recover from the disturbances affecting the system, the whole maize system as currently known might disappear.

In the case of Scenarios 2 and 3, a resilience based purely on revenue is insufficient, and nonmonetary strategic resources (e.g., maize reserves and livestock) gain importance for maintaining resilience. If these two resources are well developed, they can be used during the dry years either as a source of food (if consumed by the farmers or exchanged by food) or as a 
source of cash (if sold). Maize reserves and livestock can be accumulated during the good years and can serve as emergency food during rough years.

\subsection{A conceptual framework for implementing policies}

The ultimate purpose of resilience planning is to identify and implement policies that will ultimately contribute to increasing the resilience of particular outcomes of the system. While we do not intend to use resilience planning as a prescriptive tool, for its outcomes to be meaningful, resilience planning needs to connect with the policymaking and management world. By adding the policy implementation and management step to the approach proposed by Walker et al. (2002), we try to bridge the results of an otherwise abstract analysis with the concrete steps followed in the implementation. The result is a better understanding of the feasibility of policies and the potential challenges that need to be addressed prior to their implementation by public bodies.

In our experience, having a diagram representing, even if at a high level, a DPM system for the policies proposed is a powerful way to engage with public officials and to discuss the practical implications of the process conducted. First, the DPM system translates the policies proposed into concrete actions and process that are meaningful in the public sector's language. Second, the DPM system outlines key performance indicators for measuring the realisation of benefits. It also offers an objective way to assess the value for money of the different alternatives and to select the best policy alternative. Finally, and probably more importantly, we found that the DPM system was a powerful tool to build confidence in public officials about the outcomes of the process. For instance, public officials from the local government in Jutiapa stated the following:

"We think we can now see how the whole discussion starts to land on concrete actions we can take to help our communities. It has been a long process, but we are finally there" (Delegate from Local Government)

"I did not realise that resilience was such a complex concept. However, I think now we have a very clear direction of travel." (Delegate from Local Government) 


\section{CONCLUSIONS AND LESSONS LEARNED}

Resilience offers a very compelling framework to analyse the adaptive mechanisms an SES needs to adapt to climate change and other rapid and dramatic changes in the environment. Understanding these mechanisms might yield valuable insights for food system management to ensure the food security of vulnerable groups in the short- and mid-term future. However, the analysis of resilience beyond theoretical settings still lags behind, and there are no concrete and replicable analytical methods to move it into policymaking settings.

As an alternative, we have outlined in this paper an approach for using facilitated SD in the process of planning for resilience. Despite the fact that resilience is context specific (Marshall and Marshall, 2007), we hypothesize that the general steps and activities described in the paper apply to many contexts and systems. However, further research is needed to validate the usefulness of and improve the approach proposed in this paper.

Our experience, summarised in this paper, shows that facilitated SD offers a promising starting point for establishing a resilience planning approach. First, it offers a formal mean for engaging with stakeholders. Having facilitated discussions using diagrams eases the discussion about otherwise abstract concepts and fosters consensus about what resilience means in a particular context and how the system works while incorporating more-comprehensive and diverse perspectives in the analysis. This is fundamental in resilience planning, because including broader perspectives helps enhance the understanding of the system and its potential developments.

Second, a simulation model unlocks the analysis and allows a transition to quantitative comparisons using different characteristics of resilience. While the measures are illustrative, they offer a practical and quantifiable ground for comparing how specific policies affect resilience. As shown in the case discussed in this paper, different policies excel in different characteristics of resilience under different conditions. The results produced can be used in later stages to inform an economic assessment or a multi-criteria analysis.

Note that even the second benefit is linked to tangible outcomes. The overall benefit of the proposed method is the discussion and learning that springs out of each step of the process. As shown in this paper, participants can learn from each other and the model as they test their hypotheses about how changes in some parameters might affect the model's behaviour. The effects of these changes are not obscure; on the contrary, they are explicitly represented in the CLDs developed and discussed by and with the group. Rather than a single alternative course 
of action, the analysis provides policymakers with a more robust understanding of the leverage they have to enhance resilience.

Finally, combining SD and performance management in a DPM map provides a link to further and more-prescriptive steps of the policymaking process. The DPM map reconciles the conceptual discussion about the system as a whole and the policies that can be implemented with the concrete activities that need to be undertaken. While the DPM is still at a very high level, it works as a bridge between analysis and practice and offers a baseline for developing projects and public policies. This extra step towards implementation is, in our experience, helpful to engage with public officials and to build confidence in the feasibility and viability of the policies proposed.

It is important to highlight caveats of the proposed approach that still require further research. First, there is the issue of how to address transformation and changes in the system. In the presence of disturbances, systems might transform, changing their nature in ways that are difficult to anticipate in any model. Second, the method is limited in its means for representing actors in the system and their relationships. While some decisions are represented to some extent in the model, the interaction between actors is often simplified and aggregated in SD models. As an alternative, the socio-ecological literature has suggested using the model in roleplay games with different stakeholder groups.

\section{REFERENCES}

Andersen, D.F., \& Richardson, G. P. (1997). Scripts for group model building. System Dynamics Review, 13(2), 107-1297

Andersen, D. F., Vennix, J. a. M., Richardson, G. P., \& Rouwette, E. a. J. a. (2007). Group Model Building: Problem Structuring, Policy Simulation and Decision Support. The Journal of the Operational Research Society, 58(5), 691-694.

Barlas, Y. (1996). Formal aspects of model validity and validation in system dynamics. System Dynamics Review, 12(3), 183-210

Bianchi, C. (2016). System Dynamics for Performance Management 1 Dynamic Performance Management. Switzerland: Springer.

Biggs, R., Schluter, M., Biggs, D., Bohensky, E.L., Burnsilver, S., Cundill, G., ... West, P.C. (2012). Toward Principles for Enhancing the Resilience of Ecosystem Services. Annual Review of Environmental Resources, 37, 421-448.

Bouroncle, C., Imbach, Pablo, Läderach, P., Rodirguez, B., Medellin, C., Fung, E., ... Donatti, C. I. (2015). La agricultura de Guatemala y el cambio climático: ¿Dónde están las prioridades para la adaptación? Copenhague, Dinamarca: CGIAR Research Program on Climate Change, Agriculture and Food Security (CCAFS). 
Carpenter, S.R., \& Gunderson, L. (2001). Coping with Collapse : Ecological and Social Dynamics in Ecosystem Management. BioScience, 51(6), 451-457.

Cosenz, F. (2014). A Dynamic Viewpoint to Design Performance Management Systems in Academic Institutions: Theory and Practice. International Journal of Public Administration, 37(13), 955-969.

Cretney, R. (2014). Resilience for whom? Emerging critical geographies of socio-ecological resilience. Geography Compass, 8(9), 627-640

Davoudi, S., Brooks, E., \& Mehmood, A. (2013). Evolutionary Resilience and Strategies for Climate Adaptation. Planning Practice and Research, 28(3), 307-322.

Davoudi, S., Shaw, K., Haider, L. J., Quinlan, A. E., Peterson, G. D., Wilkinson, C., ... Davoudi, S. (2012). Resilience: A Bridging Concept or a Dead End? "Reframing" Resilience: Challenges Planning Theory \& Practice, 13(2), 299-333

Diehl, E., \& Sterman, J. D. (1995). Effects of Feedback complexity on Dynamic Decision Making. Organizational Behavior and Human Decision Processes, 62(2), 196-215.

Duit, A. (2015). Resilience Thinking: Lessons for Public Administration. Public Administration, 94(2), 364-80

FAO. (2016). Food and Agriculture Organization in Guatemala. Retrieved from http://www.fao.org/guatemala/programas-y-proyectos/lista-de-proyectos/en/

Folke, C. (2006). Resilience: the emergence of a perspective for social-ecological systems and analyses. Global Environmental Change, 16(3), 253-267.

Folke, C., Carpenter, S.R., Walker, B., Scheffer, M., \& Chapin, T. (2010). Resilience Thinking: Integrating Resilience, Adaptability and Transformability, Ecology and Society, 15(4).

Fuentes, A.R., van Etten, J., Aparaicio, A.O., Vivero, J.L. (2005). Maíz para Guatemala. FAO Guatemala. Guatemala.

Guardiola, J., Gonzáles, V., \& Vivero, J. (2006). La seguridad alimentaria: estimación de indices de vulnerabilidad en Guatemala. Trabajo presentado en la VIII Reunión de Economía Mundial. Alicante, 20, 21 y 22 de abril de 2006.

Hawes, C., \& Reed, C. (2006). Theoretical steps towards modelling resilience in complex systems. Lecture Notes in Computer Science (Including Subseries Lecture Notes in Artificial Intelligence and Lecture Notes in Bioinformatics), 3980 LNCS, 644-653. http://doi.org/10.1007/11751540_68

Herrera, H. (2017a). From Metaphor to Practice: Operationalizing the Analysis of Resilience Using System Dynamics Modelling. Systems Research and Behavioral Science, 34(4), $444-462$.

Herrera, H. (2017b). Resilience for Whom? The Problem Structuring Process of the Resilience Analysis. Sustainability, 9(7), 1196.

Herrera H. (2018) Public Policy Design for Climate Change Adaptation: A Dynamic Performance Management Approach to Enhance Resilience. In: Borgonovi E., AnessiPessina E., Bianchi C. (eds) Outcome-Based Performance Management in the Public Sector. System Dynamics for Performance Management, (pp. 425-445). Springer, Cham.

Holling, C.S. (1973). Resilience and stability of ecological systems. Annual Review of Ecology and Systematics,4(1), 1-23. 
Holling, C.S., \& Gunderson, L.H. (2002). Panarchy: Understanding transformations in human and natural systems. Island Press

König, H. J., Sghaier, M., Schuler, J., Abdeladhim, M., Helming, K., Tonneau, J. P., ... Wiggering, H. (2012). Participatory impact assessment of soil and water conservation scenarios in Oum Zessar watershed, Tunisia. Environmental Management, 50(1), 153165

Lane, D.C. (2008). The Emergence and Use of Diagramming in System Dynamics: A Critical Account. Systems Research \& Behavioral Science, 25(1), 3-23

Mahmoud, M., Liu, Y., Hartmann, H., Stewart, S., Wagener, T., Semmens, D., ... Winter, L. (2009). A formal framework for scenario development in support of environmental decision-making. Environmental Modelling and Software, 24(7), 798-808.

Marshall, N.A., \& Marshall, P.A. (2007). Conceptualizing and Operationalizing Social Resiliance within Commercial Fisheries in Northern Australia. Ecology and Society, 12(1), 1

Merriam, S. B. (2002). Introduction to qualitative research. In Qualitative research in practice: Examples for discussion and analysis. New York: John Wiley and Sons.

Morecroft, J. D. W. (2015). Strategic Modelling and Business Dynamics. A feedback systems approach.

Perrings, C. (1998). Resilience in the Dynamics of Economy-Environment Systems. Environmental and Resource Economics, 11(3-4), 503-520.

Pizzo, B. (2015). Problematizing resilience: Implications for planning theory and practice. Cities, 43, 133-140.

Randers, J. (1980). Guidelines for model conceptualization. In Elements of the system dynamics method (pp. 117-139). Cambridge, MA: MIT Press.

Richardson, G.P. (1986). Problems with causal-loop diagrams. System Dynamics Review, 2(2), $158-170$.

Richardson, G.P. (2011). Reflections on the foundations of system dynamics. System Dynamics Review, 27(3), 219-243.

Schmidhuber, J., \& Tubiello, F.N. (2007). Global food security under climate change. Proceedings of the National Academy of Sciences of the United States of America, 104(50),

SESAN (2015). Plan hambre cero en el corredor seco. Gobierno de Guatemala, Guatemala.

Stake, R.E. (1995). The art of case study research. London: Sage.

Stave, K., Kopainsky, B., Anteneh, M., Abebe, A. M., Sebhat, M. Y., Aynalem, S., ... Ayenew, M. M. (2017). Participatory System Dynamics Mapping for Collaboration and Socioecological Integration in the Lake Tana Region. In Social and Ecological System Dynamics (pp. 615-630). New York: Springer International Publishing.

Sterman, J.D. (2000). Business Dynamics. Irwin/McGraw-Hill: Boston.

Sterman, J.D., \& Sweeney, L. (2002). Cloudy skies: assessing public understanding of global warming. System Dynamics Review, 18(2), 207-240.

Swart, R.J., Raskin, P., \& Robinson, J. (2004). The problem of the future: Sustainability science and scenario analysis. Global Environmental Change, 14(2), 137-146. 
Tendall, D.M., Joerin, J., Kopainsky, B., Edwards, P., Shreck, A., Le, Q. B., ... Six, J. (2015). Food system resilience : De fi ning the concept Resilience Sustainability. Global Food Security, 6, 17-23.

Tompkins, E.L., \& Adger, W.N. (2004). Does Adaptive Management of Natural Resources Enhance Resilience to Climate Change? Ecology and Society, 9(2), 10.

Vhurumuku, E. (2014). Food Security Indicators. Nairobi.

Walker, B., Carpenter, S., Anderies, J., Abel, N., Cumming, G., Janssen, M., ... Pritchard, R. (2002). Resilience Management in Social-ecological Systems : a Working Hypothesis for a Participatory Approach. Conservation Ecology, 6(1), 14.

Walker, B., Holling, C.S., Carpenter, S.R., \& Kinzig, A. (2004). Resilience, adaptability and transformability in social--ecological systems. Ecology and Society, 9(2), 5.

WFP. (2016). World Food Programme Guatemala. Retrieved from http://www1.wfp.org/countries/guatemala

World Bank. (2003). Poverty in Guatemala.

Zagonel, A. A. (2002). Model conceptualization in group model building: A review of the literature exploring the tension between representing reality and negotiating a social order. In Proceedings of the 20th International System Dynamics Conference (Vol. 51, pp. 170182).

Zagonel, A. A. (2004). Reflecting on group model building used to support welfare reform in New York state. SUNY Albany, NY 